\title{
MARGINAL BONE LEVEL EVALUATION OF IMPLANT SUPPORTED KENNEDY CLASS I PARTIAL OVERDENTURE USING TELESCOPIC CROWNS VERSUS ACETAL RESIN CLASPS DIRECT RETAINERS
}

\author{
Ahmed A.Elwahed Youssef *
}

\begin{abstract}
Objectives : This study was conducted to evaluate and compare marginal bone level for abutments of implant supported Kennedy class I partial overdenture using Telescopic Crowns versus acetal resin clasps direct retainers after 18 month of clinical use.

Materials \& methods : Ten male partially edentulous patients (Kennedy class I) with the premolars are the last standing abutments were selected and all patients were rehabilitated with metallic partial denture supported by two osseointegrated implants one on each side of the lower arch positioned in the area of second molar and were randomly divided into two equal groups according to type of abutments retainers ,Group I; Patients were rehabilitated with Tooth Implant Supported partial overdenture with two telescopic crowns ,Group II; Patients were rehabilitated with Tooth Implant Supported partial overdenture with two Acetal Resin clasps direct retainer on each side. Evaluation by measuring marginal bone level for main abutments was made at the time of insertion, after 6 month ,after 12 month and last after 18 month using radiographic evaluation.
\end{abstract}

Results: partial overdentures retained by telescopic crowns showed significant increase in marginal bone loss as compared with Acetal resin clasps retainers.

Conclusion: using tooth implant partial overdentures retained by Acetal resin clasps shows better effect on supporting structure as compared by partial dentures with telescopic crowns retainers.

\section{INTRODUCTION}

The cast partial has been the option of choice because the lack of posterior abutments in Kennedy Class I cases excluded the possibility of fixed bridge treatment option. ${ }^{(1)}$
The design of a direct retainer is considered a prominent factor that controls the force applied to the abutment teeth. Studies conducted under a simulated condition have suggested that claspretained designs produce less torque on abutment teeth than intracoronal attachments. ${ }^{(2,3)}$

\footnotetext{
* Lecturer, Removable Prosthodontics,Faculty of oral and Dental Medicine,Future University .
} 
Most commonly, RPD clasps are made from the same alloy of the metal framework, As cobaltchromium (Co-Cr) alloy, gold and titanium alloys, although these may be un esthetic, The methods to overcome this esthetic dilemma have included covering clasps with tooth-colored resin, using lingually positioned clasps, and engaging mesial rather than distal undercuts .(4)

Thermoplastic Acetal is one of thermoplastic resins that developed the first tooth colored clasps which are flexible, don't need periodic adjusting to keep them tight ,acetal resin is very strong, resists wear and fracture. It also exhibits high creep resistance and high fatigue endurance as well as is hydrophobic, It has little or no porosity, which reduces the accumulation of biological material like plaque, which in turn resists odor and stains. ${ }^{(5,6)}$

A removable partial denture retained by telescopic crowns is an alternative treatment option to a conventional clasp retained removable partial denture. ${ }^{(7)}$

Extracoronal attachments have part or all of their mechanism outside the contour of the tooth. Their main application is in distal extension prosthesis. ${ }^{(8)}$ Although they provide superior retention, esthetics and the stresses acting on a denture base of an attachment denture was less than that of clasp denture. However, the application of these attachments exerted excessive torque to the most distal abutment, which may necessitate splinting to minimize the hazardous effects of excessive loading. ${ }^{(9)}$

It was stated stated that kennedy class I removable partial denture cases can be greatly enhanced by the addition of posterior implants. These enhanced removable partial dentures have been called implant-supported removable partial dentures. ${ }^{(10)}$

Cone-beam computed tomography has been used for several important oral and maxillofacial surgery applications especially at implant placement . All modern researches revealed excellent image quality and information acquired with Conebeam computed tomography devices for different anatomical structures. ${ }^{(11,12)}$

\section{MATERIALS AND METHODS}

Ten partially edentulous class I Kennedy's classification patients with age ranged from 55-65 years were selected from the out-patient clinic, Faculty Of Oral and Dental Medicine, Future University. all patients were rehabilitated with metallic partial denture supported by two osseointegrated implants one on each side of the lower arch positioned in the area of second molar and were randomly divided into two equal groups according to type of abutments retainers ,Group I; Patients were rehabilitated with Tooth Implant Supported partial overdenture with two telescopic crowns ,Group II; Patients were rehabilitated with Tooth Implant Supported partial overdenture with Acetal resin clasps direct retainer on each side.

\section{Surgical procedures}

\section{A. Pre-surgical preparation}

- Surgical stents were constructed (Fig.1 \& 2 )

- A hole was drilled in the implant site corresponding to the second molar area in the preoperative radiographic template (Fig.3)

\section{B. Implant selection}

A color guided implant system; V-TPS (Vacuum-Titanium Plasma Spray) coating root form, cylindrical screw, internally hexed titanium implants and self tapping expansion thread system were used. They are available in five diameters and five lengths ranging from 8 to $16 \mathrm{mms}$. The $10 \mathrm{~mm}$ length and $3.75 \mathrm{~mm}$ diameter was used. .

\section{Surgical procedures}

- Mandibular nerve block, as well as, ring infiltration anesthesia was given at the corresponding side to the surgical region

- The autoclaved surgical stent was seated in the patient's mouth to identify exact area for implant insertion. Mucoperiosteal flap was made . 
- Surgical stent was modified and introduced in the patient's mouth, to mark the exact fixture site .

- Osteotomy was made using successive drills at predetermined implant site and Implant fixtures were inserted in place and titanium cover screws of the same diameter of the implant were screwed into implant fixture. The flap was irrigated with saline, repositioned and secured by interrupted sutures. (Fig.4)

- Three months after implant placement, the patient was recalled, and Fixture position was detected by palpation with the aid of surgical stent and the site was marked and exposed .
- The cover screw was unthreaded and a healing collar of $4 \mathrm{~mm}$ length was selected, inserted and threaded into the implant by the aid of implant driver and tightened well.

\section{Prosthetic procedures :}

The selected patients were randomly divided into two equal groups, five patients each:

\section{Group I}

Patients were rehabilitated with metallic partial denture supported by two osseointegrated implants one on each side of the lower arch positioned in the area of second molar retained by two telescopic crowns retainer.

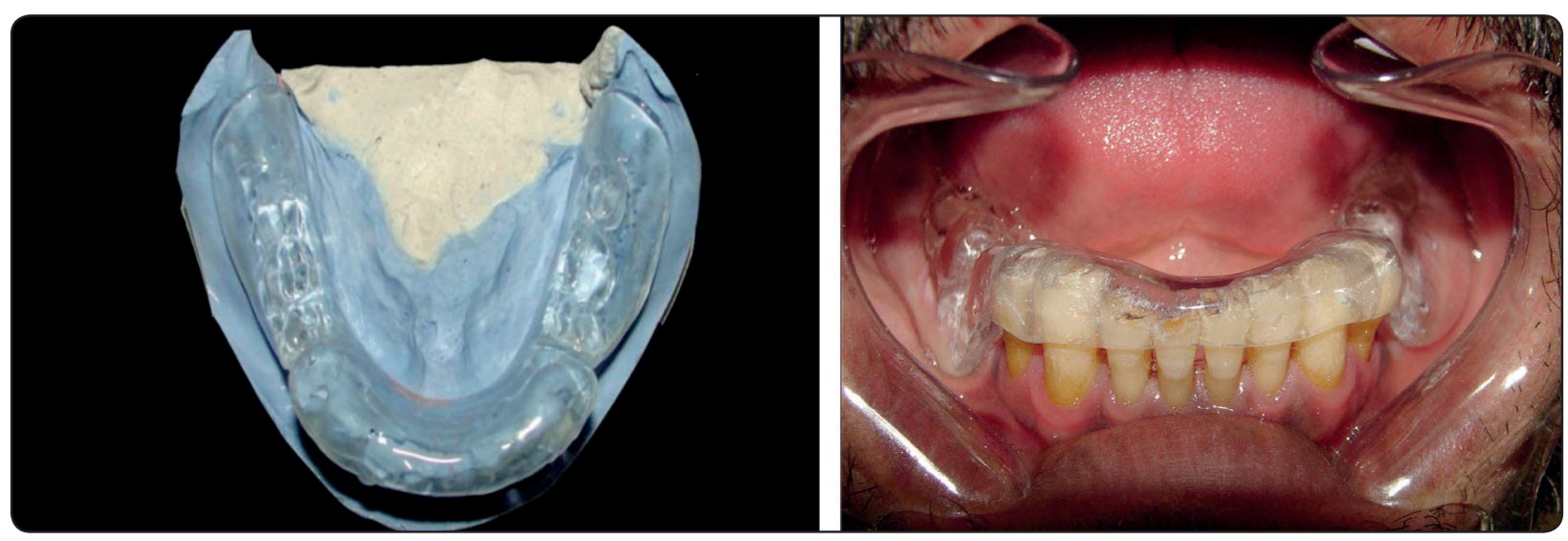

Fig. (1 \& 2) Clear heat cured acrylic resin surgical guide stent.

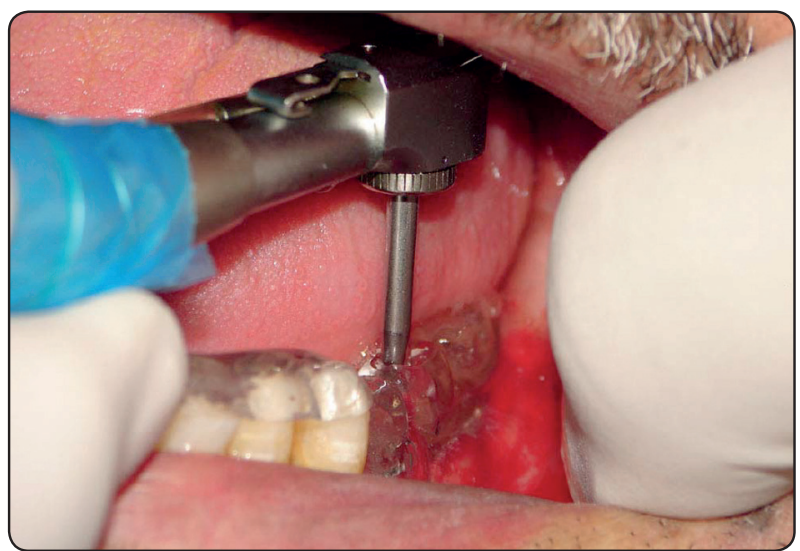

Fig. (3) Starting bone osteotomy through the surgical guiding stent.

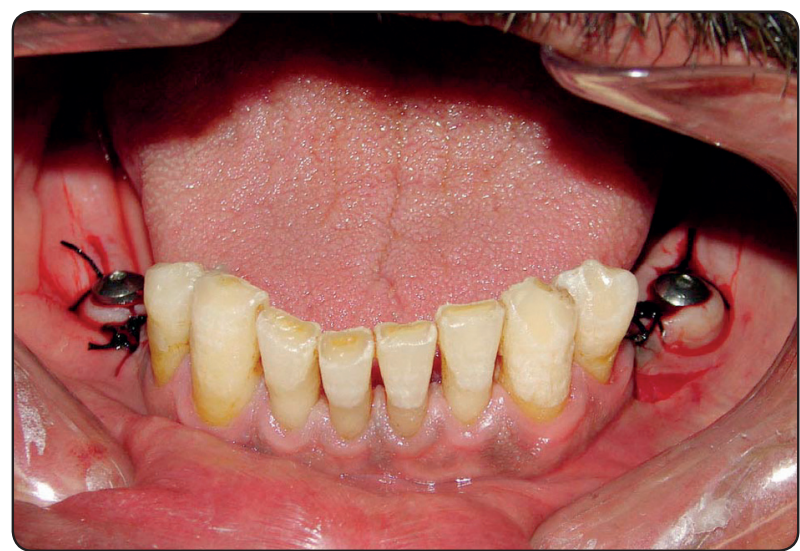

Fig. (4) Closure of the mucoperiosteal flaps with multiple sutures after screwing the healing abutments. 


\section{Group II}

Patients were rehabilitated with metallic partial denture supported by two osseointegrated implants one on each side of the lower arch positioned in the area of second molar retained by Acetal resin clasps direct retainer on each side.

\section{For group I}

Patients were rehabilitated with metallic partial denture supported by two osseointegrated implants one on each side of the lower arch positioned in the area of second molar retained by telescopic crowns direct retainer on each side.

- Proper preparation of abutments to receive telescopic crowns retainers .

- Upper and lower primary and secondary impressions were made for all patients.

- Cementation of crowns and proper try in and insertion for denture and telescopic crowns

\section{For group II}

Mesial occlusal rest seats and guiding planes were prepared on enamel surface of each abutment tooth adjacent to the edentulous areas and The rest seats were made saucer shaped with rounded angles.

Secondary impression was made for the lower arch in the pre-constructed special tray and poured in stone to produce the master cast.(Fig.5)

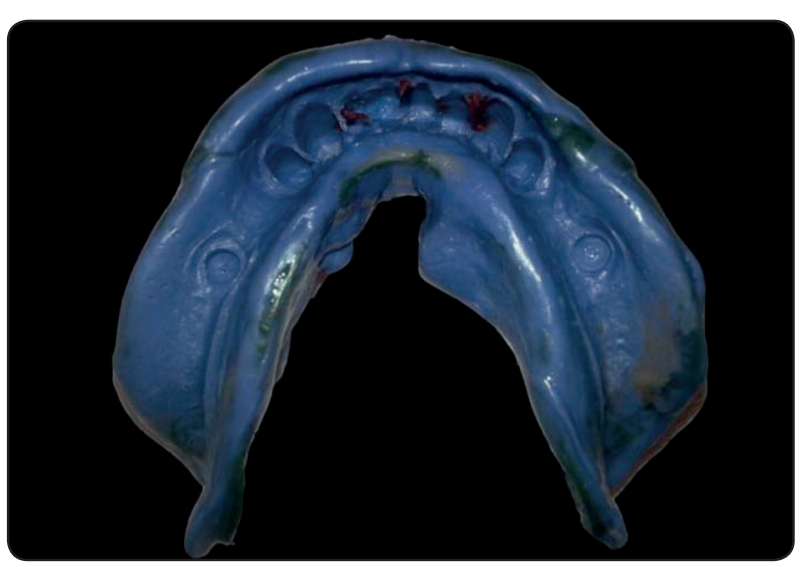

Fig. (5) Mandibular final rubber base impression.
- The resin clasp was sprued, flasked mechanically attached to metallic denture base.

- Centric occluding relation following the interocclusal wax wafer technique was made and a try in stage was made successfully.

- Final partial denture was finished, polished and delivered to the patient in the usual manner after clinical adjustments (Fig.6) .

\section{Post insertion evaluation}

Marginal bone level was measured at the time of delivery, then after six month, twelve and lastly after eighteen months using digital force meter.

\section{Radiographic evaluation:}

- Cone beam C.T. were developed and image processed.

- A line tangential to the apex and perpendicular to abutments long axes was drawn . Two lines were drawn one on the mesial and the other on the distal side of the abutment starting from the alveolar crest extended along tooth lamina dura till the tangential line at the tooth apex. (Fig. 7)

- The same procedures were done for the posterior implants. (Fig. 8)

- The amount of bone loss was calculated by subtracting the measured distances between each radiographic evaluation made at the time of denture insertion and the recall appointments.

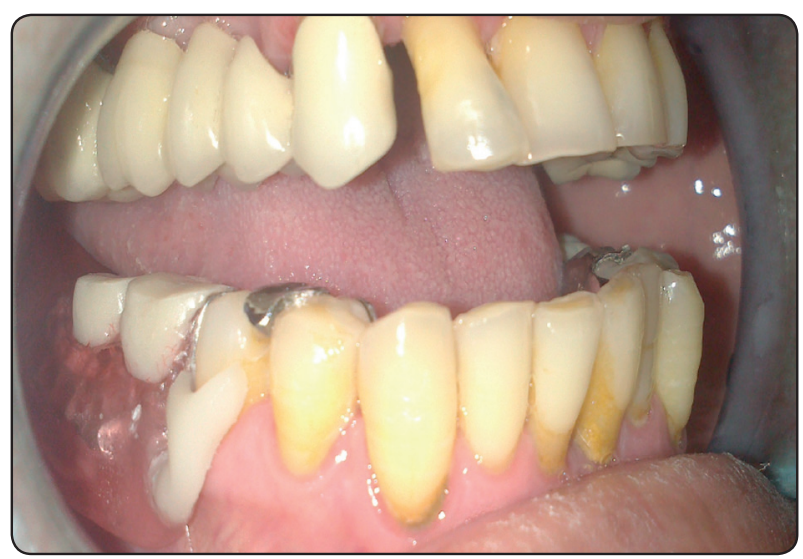

Fig.(6) Finished partial denture with Acetal resin clasps 


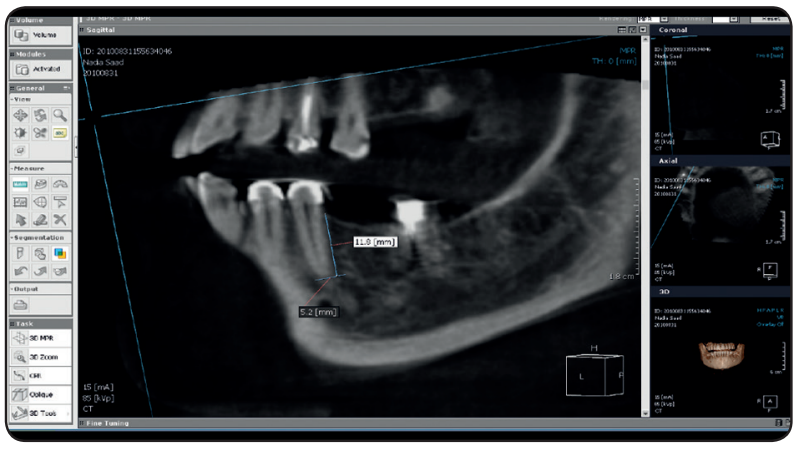

Fig. (7) Crestal bone height change Measurements around the main abutments.

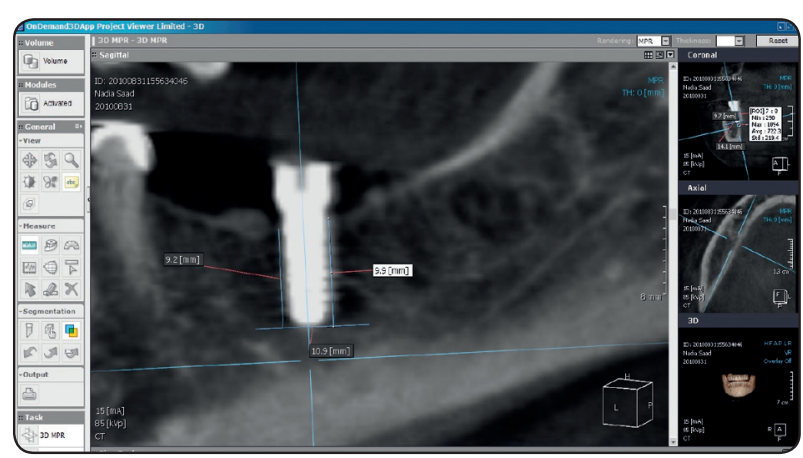

Fig. (8) Crestal bone height change Measurements around the implant.

\section{RESULTS}

\section{Relation in marginal bone level between telescopic crowns and acetal clasp direct retainers}

TABLE (1) Relation in marginal bone level of Abutment teeth for telescopic crowns and acetal resin clasp direct retainers :

\begin{tabular}{|c|c|c|c|c|c|}
\hline \multirow{2}{*}{ Treatment modality } & \multicolumn{2}{|c|}{$\begin{array}{c}\text { RPD with Telescopic crown } \\
\text { (Group I) }\end{array}$} & \multicolumn{3}{|c|}{$\begin{array}{c}\text { RPD with Acetal resin Clasps } \\
\text { (Group II) }\end{array}$} \\
\hline Time & Mean & S.D. & Mean & S.D. & P-Value \\
\hline Zero-time-6 M & 2.34 & 0.32 & 0.26 & 0.15 & $-5.05 *$ \\
\hline Zero-time-12 M & 4.28 & 0.37 & 0.44 & 0.21 & $-8.03 *$ \\
\hline Zero-time-18 M & 3.98 & 0.347 & 0.37 & 0.19 & $-7.08 *$ \\
\hline
\end{tabular}

S.D.= Standard deviation .

$$
P \text {-Value }<0.05 \text { is significant value }
$$

TABLE (2) Relation in marginal bone level for implants supporting partial denture for both groups :

\begin{tabular}{|c|c|c|c|c|c|}
\hline \multirow{2}{*}{ Treatment modality } & \multicolumn{2}{|c|}{$\begin{array}{c}\text { Implant supporting RPD with_ } \\
\text { Telescopic crown } \\
\text { (Group I) }\end{array}$} & \multicolumn{2}{c|}{$\begin{array}{c}\text { Implant supporting RPD with } \\
\text { Acetal resin Clasps } \\
\text { (Group II) }\end{array}$} & S.D. \\
\hline Time & Mean & S.D. & Mean & 0.27 & 0.005 \\
\hline Zero-time-6 M & 0.68 & 0.280 & 0.96 & 0.36 & 0.0001 \\
\hline Zero-time-12 M & 1.36 & 0.290 & 1.8 & 0.33 & 0.0009 \\
\hline Zero-time-18 M & 1.10 & 0.287 & 1.5 & \\
\hline
\end{tabular}

S.D.= Standard deviation .

$P$-Value $<0.05$ is significant value

- Data were collected for all patients at different follow-up intervals. Data were tabulated and statistically analyzed. 


\section{DISCUSSION}

Acetal resins are highly versatile engineering polymers that bridge the gap between metals and ordinary plastics. Because they offer the strength of metal and the flexibility and comfort of plastic, they make an ideal material for the fabrication of dental prostheses, particularly clasps..$^{(13)}$

The design of the finished partial denture was the same for all patients of both groups for more reliable results. the design was formulated according to the common principles and concepts followed in distal extension cases. ${ }^{(14)}$

Gingivally approach clasps (infra bulge clasps) has been though to be more retentive than occlusally approach clasps (supra bulge clasps) as it posses an inherit tripping action, Gingivally approach clasps are also though to be more esthetically than occlusal approach. ${ }^{(15,16)}$

It was found that the marginal bone loss of Acetal at the insertion visit is less than other types of retainers with significant difference, this may be due to Acetal resin has a relatively high proportional limit with little viscous flow, enabling it to behave elastically over a large enough range to be used as a material for clasp fabrication. ${ }^{(17)}$

It was concluded that though the flexural strength and modulus of elasticity were relatively low in the thermoplastic resins, they demonstrated great toughness and resistance to fracture; thermoplastic resins could withstand stress through a considerable degree of deflection, indicating that they have sufficient longevity for repeated insertion and removal from the oral cavity. ${ }^{(18)}$

In this study the mean values for the amount of marginal bone loss around the abutments teeth in group I telescopic crowns retained group was $4.28 \mathrm{~mm}$ while in group II RPI retained group was $0.44 \mathrm{~mm}$, twelve months after wearing the partial overdenture. The significant difference between the two groups at the end of one-year follow up period may be due to the strain concentrated on the periodontal ligaments of abutment teeth and its surrounding tissues from repeated removal forces of prosthesis retained by telescopic crowns. In agreement with Gungor et al. this strain concentrated on the bone and the tensile stresses on the periodontal tissues might cause resorption around the cervical region. ${ }^{(19)}$

Consequently rigidity of telescopic crowns of group I retainers reflects posteriorly on posterior implants by decreasing the stresses upon them lead to significantly less marginal bone loss than group II retained by acetal resin clasp with more flexibility and that also reflects posteriorly on marginal bone loss around posterior implants leading to significant marginal bone loss.

\section{CONCLUSION}

Within the limitation of the results of this study, it could be concluded that Using partial denture with gingival approach clasps made from acetal resin showed better effect on marginal bone loss as compared by using partial dentures with telescopic crown retainers .

\section{REFERENCES}

1- George E Bambra : prosthetic replacement options for restoring kennedy class I bilateral extension cases. AEGIS Communications, volume 4, issue 1, 2008.

2- Chou TM, Caputo AA, Moore DJ and Xiao B: Photoelastic analysis and comparison of force-transmission characteristics of intracoronal attachments with clasp distal-extension removable partial dentures. J Prosthet Dent, 62(3): 313-9,2001.

3- Chou TM, Eick JD, Moore DJ and Tira DE: Stereophotogrammetric analysis of abutment tooth movement in distal-extension removable partial dentures with intracoronal attachments and clasps. J Prosthet Dent, 66(3): 343-9, 1991.

4- Ozcan M.: The use of chairside silica coating for different dental applications: a clinical report. J Prosthet Dent; 87:469-72, 2002. 
5- Kutsch V.K., Joe Whitehouse DMD, Kris Schermerhorn DDS\& Robert Bowers CDT: The evaluation and advancement of Dental Thermoplastics. Dental town Magazine; P.52-56, 2003.

6- Schermerhorn K.E: Esthetic resin partial denture ,www. oregondental.org., 2007.

7- Widbom T, Lofquist L, Widbom C, Soderfeldt B and Kronstrom M: Tooth-supported telescopic crown-retained dentures: an up to 9-year retrospective clinical follow-up study. Int J Prosthodont, 17(1): 29-34, 2004.

8- Preiskel HW. 1st ed. Precision attachments in prosthodontics: the application of intracoronal and extracoronal attachments, Chicago: Quintessence Pub Co.,1984.

9- Saito M, Miura Y, Notani K and Kawasaki T: Stress distribution of abutments and base displacement with precision attachment- and telescopic crown-retained removable partial dentures. J Oral Rehabil, 30(5): 482-7, 2003.

10- Carpenter J: Implant-enhanced removable partial denture treatment, Implant dentistry today 2010.

11- Ito K, Gomi Y, Sato S, Arai Y and Shinoda K: Clinical application of a new compact CT system to assess 3-D images for the preoperative treatment planning of implants in the posterior mandible A case report. Clin Oral Implants Res, 12(5): 539-42,2001.
12- Hashimoto K, Arai Y, Iwai K, Araki M, Kawashima S and Terakado M: A comparison of a new limited cone beam computed tomography machine for dental use with a multidetector row helical CT machine. Oral Surg Oral Med Oral Pathol Oral Radiol Endod, 95(3): 371-7,2003.

13- Lekha K, Savitha NP, Meshramkar Roseline \& Ramesh K Nadiger: Acetal resin as an esthetic clasp material. J. Interdiscip Dentistry ; 2:11-4, 2012.

14- Hassan O.: Comparitive evaluation of versacryl clasps in distal extension cases. M.D.S Thesis, Faculty of Oral and Dental Medicine, Cairo University, 2012.

15- Donovan T.E \& Cho G.C: Esthetic consedration with removable partial dentures,J. Calif. Dent. Assoc., 31(7): P.551-557, 2003.

16- McGiveny GP\& Castleberry AB: McCraken's Removable partial prosthodontics, $12^{\text {th }}$ ed. Mosby Co., St Louis 17,68 ; 236-241, 2012.

17- Arda T, Arikan A: An in vitro comparison of retentive force and deformation of Acetal resin and cobalt chromium clasps ,J. Prosth. Dent, Vol 94. Issue 3 Pg 267-274, 2005.

18- Takabayashi Y. : Characteristics of denture thermoplastic resins for non metal clasp dentures. Dent Mater J; 29:35361,2010 .

19- Gungor MA, Artunc C, Sonugelen M and Toparli M: The evaluation of the removal forces on the conus crowned telescopic prostheses with the finite element analysis (FEA). J Oral Rehabil, 29(11): 1069-75, 2002. 